\title{
Understanding the Transmissibility of Cucumber Green Mottle Mosaic Virus in Watermelon Seeds and Seed Health Assays
}

\author{
Xuelian Sui, ${ }^{1,2}$ Rugang Li, ${ }^{2}$ Md Shamimuzzaman, ${ }^{2}$ Zujian Wu, ${ }^{1, \dagger}$ and Kai-Shu Ling ${ }^{2, \dagger}$ \\ ${ }^{1}$ State Key Laboratory of Ecological Pest Control for Fujian and Taiwan Crops, Fujian Province Key Laboratory of Plant Virol- \\ ogy, Institute of Plant Virology, Fujian Agriculture and Forestry University, Fuzhou, China; and ${ }^{2}$ U.S. Vegetable Laboratory, \\ USDA-Agricultural Research Service, Charleston, SC, U.S.A.
}

\begin{abstract}
Cucumber green mottle mosaic virus (CGMMV), an emerging tobamovirus, has caused serious disease outbreaks to cucurbit crops in several countries, including the United States. Although CGMMV is seedborne, the mechanism of its transmission from a contaminated seed to germinating seedling is still not fully understood, and the most suitable seed health assay method has not been well established. To evaluate the mechanism of seed transmissibility, using highly contaminated watermelon seeds collected from CGMMV-infected experimental plants, bioassays were conducted in a greenhouse through seedling grow-out and by mechanical inoculation. Through natural seedling grow-out, we did not observe seed transmission of CGMMV to germinating seedlings. However, efficient transmission of CGMMV was observed using

bioassays on melon plants through mechanical inoculation of seed extract prepared from CGMMV-contaminated seeds. Understanding the seedborne property and the ease of mechanical transmission of CGMMV from a contaminated seed to seedling is an important finding. In comparative evaluation of various laboratory techniques for seed health assays, we found that enzyme-linked immunosorbent assay and loop-mediated isothermal amplification were the most sensitive and reliable methods to detect CGMMV on cucurbit seeds. Because CGMMV is a seedborne and highly contagious virus, a new infection might not result in a natural seedling grow-out; it could occur through mechanical transmission from contaminated seeds. Therefore, a sensitive seed health test is necessary to ensure CGMMV-free seed lots are used for planting.
\end{abstract}

Cucumber green mottle mosaic virus (CGMMV) in the genus Tobamovirus, family Virgaviridae, was first described in 1935 infecting cucumber in England (Ainsworth 1935). The virus has become a major reemerging viral pathogen that causes serious yield losses to a number of cucurbit crops worldwide, including cucumber (Cucumis sativus), watermelon (Citrullus lanatus), melon (Cucumis melo), squash (Cucurbita moschata), and bottle gourds (Lagenaria siceraria) (Dombrovsky et al. 2017). In recent years, CGMMV has significantly expanded its geographic distribution from its centers of epidemic origin in Europe (Borodynko-Filas et al. 2017; Budzanivska et al. 2007; CABI 2015; CABI/EPPO 2015; Norwegian Scientific Committee for Food Safety 2008; Slavokhotova et al. 2016; Varveri et al. 2002) and Asia (Ali et al. 2004; Antignus et al. 1990; Chen et al. 2006; Choi 2001; Liu et al. 2009, 2017; Massumi et al. 2007; Reingold et al. 2013; Shim et al. 2005; Yoon et al. 2008) to North America (Ling et al. 2014; Tian et al. 2014) and Australia (Australian Government Department of Agriculture and Water Resources 2017; Tesoriero et al. 2015). These global outbreaks of

${ }^{\dagger}$ Corresponding authors: Z. Wu; wuzujian@126.com and K.-S. Ling; kai.ling@ars.usda.gov

Funding: This work was supported in part by grants from the USDA, National Institute of Food and Agriculture Specialty Crop Research Initiative program SCRI 2015-51181-24285 and the Alberta Crop Industry Development Fund (2014C005R) to K.-S. Ling. A generous scholarship provided to X. Sui by the China Scholarship Council (no. 201408350066) is greatly appreciated.

*The $\boldsymbol{e}$-Xtra logo stands for "electronic extra" and indicates that one supplementary figure and three supplementary tables are published online.

The author(s) declare no conflict of interest.

Accepted for publication 19 December 2018.

This article is in the public domain and not copyrightable. It may be freely reprinted with customary crediting of the source. The American Phytopathological Society, 2019.
CGMMV have caused serious concerns to cucurbit industries and vegetable seed companies worldwide.

The accelerated geographical expansion and increased severity of disease outbreaks from CGMMV in various cucurbit crops are likely caused by transmission of the virus in contaminated commercial seed lots through ever-expanding activities of off-shore hybrid seed production, global seed trade, and intensive cucurbit production (i.e., cucurbit grafting and protected production) (Dombrovsky et al. 2017).

Although the natural host range of CGMMV is narrow and restricted to the family Cucurbitaceae, a number of weed plants in nine different families have been identified as alternative reservoir hosts (Dombrovsky et al. 2017). CGMMV typically causes mottle mosaic symptoms on leaves and distortion of fruits. However, symptoms may vary on different plant species (Fig. 1) infected by various virus isolates (Mandal et al. 2008).

CGMMV is a stable virus in the environment and is easily transmitted mechanically, through contact of healthy cucurbit plants with contaminated seeds, water, soil, or plant sap (Mandal et al. 2008). There is some general knowledge regarding the seed-borne nature of CGMMV in cucurbit seeds (Choi 2001; Liu et al. 2014; Wu et al. 2011), but the mechanism of seed transmission is still not well understood. To determine possible transmission through the process of pollination, Liu et al. (2014) were successful in generating CGMMV infection to the pollinated plants when male flowers (stamens and pollen) picked from a CGMMV-infected plant were used to rub against the stigma of female flowers in uninfected cucumber plants. This transmission through artificial pollination does not necessarily imply a true pollen transmission occurrence, because free pollen was not used in the assay (Liu et al. 2014). In addition, pollen-containing anther and filament-forming stamens are maternal tissues that are likely contaminated with the virus. Owing to the ease of mechanical transmission of CGMMV, infection to the pollinated plants was most likely due to mechanical transmission of the virus from contaminated anthers used for pollination and not necessarily through a true pollen transmission event (Liu et al. 2014). Therefore, it is important to distinguish between seed-borne and seed transmission, in terms of whether a virus can or cannot be transmitted to germinating seedlings. Additional studies are needed to clarify the nature of virus transmission to seedlings through natural seed 
germination or by mechanical transmission of CGMMVcontaminated seeds. Because the current seed treatment procedures are not able to fully deactivate the virus infectivity on the CGMMV-contaminated seeds (Reingold et al. 2015), a rigorous seed testing program with a sensitive seed health test method is necessary to ensure the virus-free status of the seed lot used for seedling germination.

Current available methods for CGMMV detection include enzyme-linked immunosorbent assay (ELISA), lateral flow device (including ImmunoStrip), reverse transcription polymerase chain reaction (RT-PCR), real-time quantitative RT-PCR (qRT-PCR), and reverse transcription loop-mediated isothermal amplification (RTLAMP) (Chen et al. 2008; Li et al. 2013; Nematollahi et al. 2014). Among these detection methods, ELISA was widely used as a routine assay for the detection of CGMMV in field surveys (Varveri et al. 2002; Zhang et al. 2009). However, owing to the presence of genetic diversity among CGMMV populations in the world (Dombrovsky et al. 2017), various sources of commercial ELISA kits for CGMMV may not be reliable in detecting all CGMMV isolates in seed samples that have a low virus titer. The RT-LAMP assay developed by Notomi et al. (2000) has been proven to be a rapid, sensitive, simple, and inexpensive method for virus detection (Le et al. 2010; Li and Ling 2014; Liu et al. 2010; Zhou et al. 2012). Other molecularbased detection methods, including RT-PCR (Kim et al. 2003; Varveri et al. 2002) and qRT-PCR (Chen et al. 2008) have also been developed for CGMMV detection in plant tissue. However, to achieve realistic risk assessment in a seed health assay, an effective bioassay would be necessary to be incorporated as a part of the testing program to confirm virus infectivity of CGMMV particles detected using various laboratory detection methods.

In this study, we evaluated the transmissibility of CGMMV on contaminated watermelon seed and conducted comparative evaluation of various molecular and serological methods for seed health assays. We recommend incorporating a bioassay as a means to validate the viability of CGMMV detected on a cucurbit seed sample.

\section{Materials and Methods}

Virus isolates and generation of CGMMV-contaminated watermelon seeds. The CGMMV isolate ABCA13-01 (GenBank accession no. KP772568) originally collected on cucumber plants from a greenhouse in Canada (Ling et al. 2014) was maintained on cantaloupe plants inside an insect-proof bug dome through mechanical inoculation. To generate CGMMV-contaminated seeds, seedlings from a susceptible line of watermelon germplasm were used in this study. Virus inoculum was prepared by grinding CGMMVinfected watermelon leaves in $0.1 \mathrm{M}$ phosphate buffer $(\mathrm{pH} 7.0)$ in a plastic sample bag using a Homex-6 tissue homogenizer (BioReba, Switzerland). In a containment greenhouse, watermelon seedlings at two- to three-leaf stage were inoculated with the prepared CGMMV inoculum. Confirmation of CGMMV infection was determined through symptom observation and appropriate tests as described in the following. Fruits were generated through hand pollination on the diseased watermelon plants. Seeds were extracted from mature fruits to obtain CGMMV-infected seeds, which were used to study seed transmissibility and for evaluation of various seed health test methods. In addition, isolates of squash mosaic virus (SqMV) and melon necrotic spot virus (MNSV) were collected locally.

Seedling germination to determine potential seed transmission. CGMMV-contaminated seeds were germinated in an artificial soil mixture supplemented with slow-release fertilizer (Osmocote), and seedlings were maintained in a greenhouse at 25 to $30^{\circ} \mathrm{C}$ under natural sun light. Symptom development on the germinated seedlings was observed weekly. Presence of CGMMV in seeds and seedlings was determined using ELISA or qRT-PCR as described in the following.

Mechanical transmission to seedlings using CGMMVcontaminated seed extract. To determine mechanical transmissibility of CGMMV from contaminated seed extract to seedlings, a virus inoculum was prepared by grinding a single CGMMV-contaminated watermelon seed in $2.0 \mathrm{ml}$ of $0.1 \mathrm{M}$ phosphate buffer $(\mathrm{pH} 7.0)$ in a plastic sample bag and soaking for $30 \mathrm{~min}$ on ice. Three healthy cantaloupe seedlings at the two- to three-leaf stage were mechanically inoculated with the prepared seed extract as virus inoculum and maintained inside a containment greenhouse. Symptoms were observed weekly up to 8 weeks, and presence of CGMMV was determined using a CGMMV ELISA reagent kit (Agdia, U.S.A.) following the manufacturer's instructions.

Development of an RT-LAMP assay for CGMMVspecific detection. Based on multiple sequence analysis of several



A. Melon Cucumis melo 'Athena'

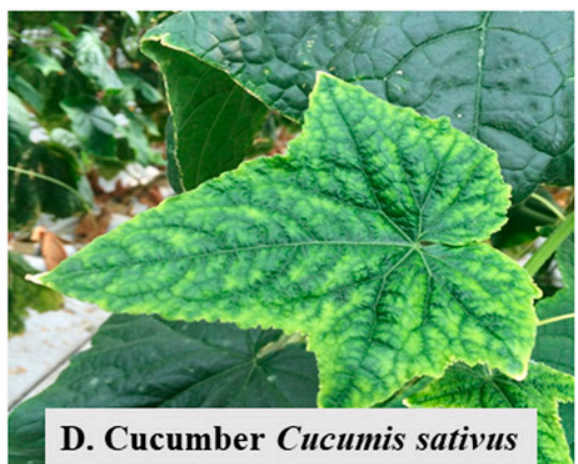

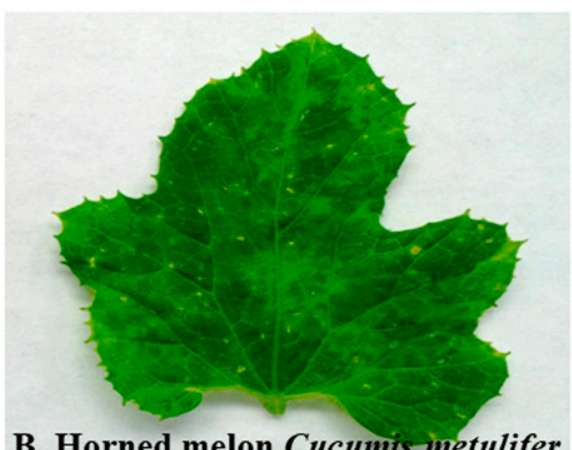

B. Horned melon Cucumis metulifer



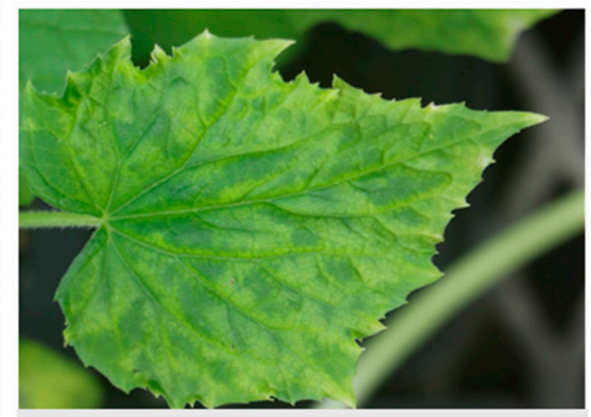

C. Bottle gourd Lagenaria siceraria

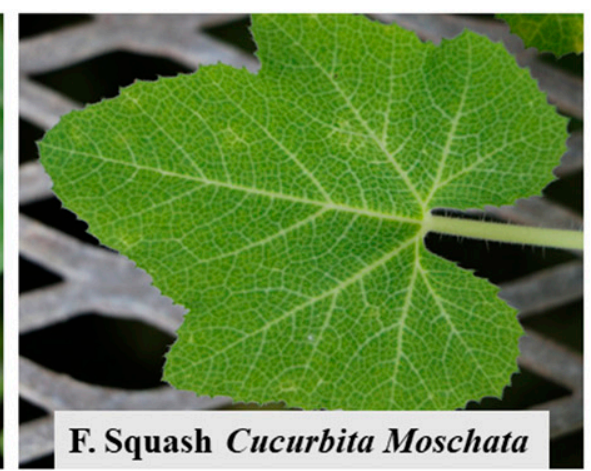

Fig. 1. Typical symptom expression on systemic leaves in various cucurbit plants. A, Melon Cucumis melo 'Athena'. B, Horned melon Cucumis metulifer. C, Bottle gourd Lagenaria siceraria. D, Cucumber Cucumis sativus. E, Watermelon Citrullus lanatus. F, Squash Cucurbita moschata. 
CGMMV isolates (Supplementary Fig. S1), a 254-bp conserved sequence region was selected to design primers for RT-LAMP. The set of four primers (F3, B3, FIP, and BIP) was designed using PrimerExplorer V4 software (http://primerexplorer.jp/elamp4.0.0/index. html). The loop primers (Loop F and Loop B) were added according to loop sequences (Fig. 2A). Total RNA was extracted from CGMMV-infected watermelon plant leaf tissue using TRIzol reagent (Invitrogen, U.S.A.) following the manufacturer's instructions. The RT-LAMP assay was performed using total RNA with an RNA amplification kit (RT-LAMP) from Eiken Chemical (Japan) according to the manufacturer's protocol. The reaction was conducted in a total volume of $25.0 \mu \mathrm{l}$ and consisted of $2 \mu \mathrm{l}$ each of FIP and BIP primers $(20 \mu \mathrm{M}), 0.25 \mu \mathrm{l}$ each of $\mathrm{F} 3$ and B3 primers $(20 \mu \mathrm{M}), 1 \mu \mathrm{l}$ each of Loop F and Loop B primers $(20 \mu \mathrm{M}), 12.5 \mu \mathrm{l}$ of $2 \times$ reaction buffer, $1 \mu \mathrm{l}$ of enzyme mix, and $1.0 \mu \mathrm{l}$ total RNA (Li and Ling 2014). The mixture was incubated at $65^{\circ} \mathrm{C}$ for $60 \mathrm{~min}$, and the reaction was terminated by heating to $95^{\circ} \mathrm{C}$ for $2 \mathrm{~min}$. RT-LAMP products were analyzed on a $2 \%$ agarose gel or by addition of $1.0 \mu \mathrm{l}$ of $1: 10$ diluted SYBR Green I (Invitrogen) for visual inspection.

For seed health assays, RT-LAMP was performed as described using crude tissue extract prepared in the following for qRT-PCR.

Seed materials. CGMMV-contaminated watermelon seeds used in this study were collected from CGMMV-infected watermelon fruits. The presence of virus was confirmed using an ELISA reagent specific to CGMMV (Agdia). In seed health testing, each sample contained one CGMMV-contaminated watermelon seed and a certain number of healthy cantaloupe seeds $(300,500,1,000,2,000$, 3,000 , and 5,000 seeds). Seeds in each sample were smashed with a hammer and homogenized with Homex-6 (Bioreba, Switzerland).

Seed health testing by ELISA and ImmunoStrip. The new ELISA and ImmunoStrip kits were kindly provided by Agdia using their newly developed antibodies against CGMMV (Agdia) and were used for seed health tests according to the manufacturer's instructions, with minor modifications for sample preparation. Two volumes of the extraction buffer to one part of smashed seed sample were homogenized using a Homex-6 in a plastic sample bag. All extracts were settled at room temperature for $30 \mathrm{~min}$ before the tests were completed. Each sample was performed in three replicates.

Seed health testing by qRT-PCR. The simple dilution of crude tissue extract of each seed lot was used as a template in both qRTPCR and RT-LAMP assays. The smashed seed lots were homogenized with 2 volumes of $0.1 \mathrm{M}$ Tris- $\mathrm{HCl}, \mathrm{pH} 8.0$, in a homogenizer bag by Homex-6 (Li and Ling 2014; Li et al. 2014) and soaked at room temperature for $30 \mathrm{~min}$. The supernatant was diluted to 1: 1,000 with diethylpyrocarbonate-treated water, which was ready to be used as a template in qRT-PCR and RT-LAMP.

The CGMMV-specific primers and probe used for qRT-PCR followed that of Chen et al. (2008), with the forward primer 5'-GCA

A

F3

F2

5114 GACTTYAGTGTAGTTAAAGCTCAGAGCTATGAATCCCTCGTGCCTGTCAAGTTGTTGCGTGGTG

5178 TTGATCTTACAAAACACCTTTATGTCACATTGTTGGGCGTGTGGTTTCTGGTGTATGGAACGT 5242 ACCGGAATCCTGTAGGGGTGGTGCTACTGTTGCTCTGGTTGACACAAGGATGCATTCTGTTGCA

5306 GAGGGAACTATATGCAAATTTTCAGCTOCCGCCACCGTCCGCGAATTCTCTGTTAGGTTCAT B2

$\begin{array}{ll}\text { F3 } & \text { 5'-GACTTYAGTGTAGTTAAAGCTCAGAG-3' } \\ \text { B3 } & \text { 5'-ATGAACCTAACAGAGAATTCGC-3' } \\ \text { FIP (F1C+F2) } & \text { 5'-CCAGAAACCACAACGCCCAAC-TCGTGCCTGTCAAGTTGT-3' } \\ \text { BIP (B1C+B2) } & \text { 5'-CTGTAGGGGTGGTGCTACTGTTGCT-GTGGCGGGAGCTGAA-3' } \\ \text { Loop F } & \text { 5'- TGTAAGATCAACACCACGC-3' } \\ \text { Loop B } & \text { 5'- GATGCATTCTGTTGCAGA-3' }\end{array}$

Fig. 2. Development of loop-mediated isothermal amplification (LAMP) for cucumber green mottle mosaic virus (CGMMV) detection. A, Nucleotide sequence of the 254-bp conserved region recognized by the LAMP primers. The sequence of primer is indicated by arrow line. Numbers at left correspond to the nucleotide position in CGMMV movement protein (CGMMV ABCA13-01, GenBank accession no. KP772568). B, Specificity of the reverse transcription LAMP (RT-LAMP). M = 1kb DNA ladder (Promega); lane 1 = CGMMV; lane 2 = squash mosaic virus; lane 3 = melon necrotic spot virus; and lane 4 = nontemplate control. C, Sensitivity of the RT-LAMP. Purified RNA from CGMMV-infected watermelon was 10-fold serial diluted from 1:10 (lane 1) to 1:10 ${ }^{9}$ (lane 9); lane $10=$ healthy control; lane $11=$ nontemplate control; and $\mathrm{M}=1 \mathrm{~kb}$ DNA ladder.
TAGTGCTTTCCCGTTCAC-3', the reverse primer 5'-TGCAGAAT TACTGCCCATAGAAAC-3', and the TaqMan probe $5^{\prime}$-CGGTTTG CTCATTGGTTTGCGGA-3' labeled with 6-carboxyfluorescein (FAM) and $N, N, N^{\prime}, N^{\prime}$-tetramethyl-6-carboxyrhodamine (TAMRA) at the $5^{\prime}$ and $3^{\prime}$, respectively. The qRT-PCR was conducted using a Takara One Step Ex Taq qRT-PCR Kit (Clontech, U.S.A.) following the manufacturer's protocol, with some modifications. Each $20-\mu 1$ reaction consisted of $0.5 \mu \mathrm{l}$ of forward primer $(10 \mu \mathrm{M}), 0.5 \mu \mathrm{l}$ of reverse primer $(10 \mu \mathrm{M}), 9.5 \mu \mathrm{l}$ of $2 \times$ reaction mix, $0.5 \mu \mathrm{l}$ of Ex Taq HS mix $(5 \mathrm{U} / \mu \mathrm{l}), 0.5 \mu \mathrm{l}$ RTase mix $(5 \mathrm{U} / \mu \mathrm{l}), 0.5 \mu \mathrm{l}$ of probe $(10 \mu \mathrm{M}), 0.4 \mu \mathrm{l}$ of Ref Dye (1:100 diluted), and $1 \mu l$ of RNA template. Thermal cycling was carried out on an Mx3000P real-time PCR system (Stratagene, U. S.A.), with reverse transcription at $50^{\circ} \mathrm{C}$ for $30 \mathrm{~min}$, denaturation at $95^{\circ} \mathrm{C}$ for $2 \mathrm{~min}$, followed by 40 cycles of denaturation at $95^{\circ} \mathrm{C}$ for $10 \mathrm{~s}$, and annealing at $60^{\circ} \mathrm{C}$ for $30 \mathrm{~s}$.

\section{Results}

Seedling grow-out to determine potential seed transmission of CGMMV on watermelon. To evaluate the rate of virus contamination on the extracted seeds, 10 seeds were randomly selected and individually tested for the presence of the virus using CGMMVspecific RT-PCR. These experimental seeds were extracted from fruits collected from a CGMMV-infected watermelon plant in a greenhouse. Results showed that each and every one of these freshly extracted seeds was positive for CGMMV (Supplementary Table $\mathrm{S} 1)$. Thus, the virus-contamination rate in experimental seeds used in this study was $100 \%$.

To determine any potential seed to seedling transmission of CGMMV, seedling grow-out of watermelon seeds was evaluated through a natural germination process. A total of 108 seeds were germinated in three replicates (36 seeds per replicate). These watermelon seeds were collected from experimental watermelon plants that were infected by CGMMV and confirmed for the presence of the virus. These contaminated seeds were germinated individually in a plastic seedling tray with potting soil and maintained in a containment greenhouse for seedling growth and symptom observation weekly for 8 weeks after germination, or seedlings in the four- to five-leaf stage. We did not observe typical disease symptoms in any of the 108 test seedlings. To investigate any potential presence of CGMMV on those asymptomatic plants, we used CGMMVspecific qRT-PCR to individually test each of the 36 seedlings in one replicate. Among 36 samples tested, two of them (nos. 13 and 25) had cycle threshold $(\mathrm{Ct})$ values $(\mathrm{Ct}: \sim 28.00)$ near the threshold (Ct: 31.00) (Supplementary Table S2). However, an additional ELISA test could not confirm the presence of CGMMV in these two seedlings. Therefore, in grow-out tests using these highly contaminated experimental seeds, no seed to seedling transmission of CGMMV was observed through a natural germination process.

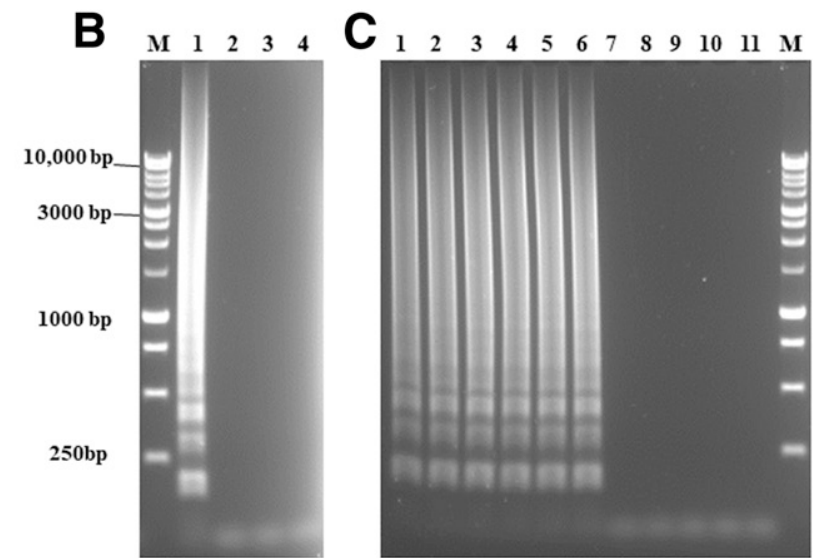


Mechanical transmission of CGMMV from contaminated seed extract to seedlings. To evaluate viability of CGMMV particles detected on the contaminated watermelon seeds that could initiate a new infection, we conducted bioassays through mechanical inoculation using an inoculum from seed extract to healthy melon seedlings with three replicates. Three weeks postinoculation, mosaic symptoms, indicating a potential infection, were observed in one of the three test melon plants inoculated from one of the three replicates (Fig. 1). In addition to the observed symptom expression, presence of CGMMV was confirmed using a commercial ELISA kit. Only one of the three replicates with one of the three inoculated plants developed typical disease symptoms (mosaic and mottling on systemic leaves), which tested positive for CGMMV with a mean absorbance value of 2.352 (Table 1). These results demonstrated that CGMMV particles on the contaminated seeds were viable and could be transmitted mechanically from a contaminated seed to a healthy seedling. To evaluate symptom expression on different types of cucurbit plants, varying levels of symptom expression were observed on the inoculated plants (Fig. 1).

Development of an RT-LAMP assay for CGMMV detection. Using total plant RNA $(1,000 \mathrm{ng} / \mu \mathrm{l})$ extracted from CGMMVinfected watermelon leaf tissue, RT-LAMP generated ladder-like DNA fragments upon agarose gel electrophoresis (Fig. 2B). To test for its specificity, the RT-LAMP produced ladder-like DNA fragments only in samples containing CGMMV RNA, with no crossreactivity to two nontarget seed-borne viruses, SqMV and MNSV (Fig. 2B). To evaluate its sensitivity, the purified RNA was 10-fold serially diluted from $1: 10$ to $1: 10^{9}$. The RT-LAMP assay was able to generate positive products for up to $1: 10^{6}$ dilution $\left(» 4 \times 10^{-5}\right.$ $\mathrm{ng} / \mu \mathrm{l}$ of total RNA) on a $2 \%$ agarose gel (Fig. 2C).

Improvement of ELISA reagent set for CGMMV. A new version of an ELISA kit was recently developed by Agdia using an antibody developed against a California isolate of CGMMV. To evaluate its sensitivity to CGMMV, comparative analysis was conducted against serially diluted CGMMV-infected watermelon leaf tissue between the old and the new version of ELISA kits. Results showed that this new ELISA kit produced stronger absorbance readings in the same samples under each dilution and was at least 10 times more sensitive than the older version of the ELISA kit (Fig. 3C).

Comparative evaluation of four CGMMV-specific detection methods for seed health assay. To select the most appropriate method for seed health testing, we evaluated the sensitivity and applicability of four CGMMV-specific detection methods for seed health assays (Table 2). In this experiment, the sensitivity was determined by spiking one CGMMV-contaminated watermelon seed into various numbers of healthy melon seeds prior to sample processing. The applicability was determined by the length of time used in sample processing plus the reliability of the test results.

For testing seed extracts, dilutions from 1:300 to 1:3,000 gave strong ELISA readings (mean $\mathrm{OD}_{405 \mathrm{~nm}}: 1.038$ to 2.619 ), whereas the 1:5,000 dilution was still 0.663 (Fig. 3D). Consistent results were generated from three replicates.

To evaluate the possibility of using ImmunoStrips for seed health tests, all the tested seed extracts with various dilutions from 1:300 to 1:5,000 showed both a control line and a test line, indicating CGMMV was detectable up to the 1:5,000 seed dilution (Fig. 3B). However, the test lines in all dilutions were not observable until after a $30 \mathrm{~min}$ incubation, which typically only takes 5 to $10 \mathrm{~min}$. The lines from each dilution of seed extract were much weaker than that of the positive control using infected leaf tissue (Fig. 3B).

To evaluate the possibility of using qRT-PCR for a seed health test, the result was considered as positive when the Ct value was under 35 or based on empirical data. Crude seed extract was not a good template for qRT-PCR, because $\mathrm{Ct}$ values were around the threshold in dilutions up to 1:1,000 and could not be clearly differentiated from the negative results (Supplementary Table S3). Therefore, qRT-PCR using crude sample preparations was not suitable for a seed health test.

To evaluate the newly developed RT-LAMP assay as a seed health test, using SYBR Green I staining, through visual observation, positive reactions turned to green whereas negative reactions appeared orange. Positive RT-LAMP products were visually observable in samples with 1:300 to 1:2,000 dilutions, whereas the reactions of 1:3,000 and 1:5,000 dilutions were negative for CGMMV (Fig. $3 \mathrm{~A})$. The results of this test were repeatable in three replicates, and the whole process took only $1.5 \mathrm{~h}$ to complete.

\section{Discussion}

CGMMV is a seed-borne virus on cucurbit seeds. However, the nature of seed transmissibility of CGMMV from a contaminated seed to its germinating seedling is not well characterized. Using experimental watermelon seeds collected from CGMMV-infected plants, it can be concluded that although all tested seeds were positive for CGMMV, seed-to-seedling transmission was rare, likely owing to the absence of the virus in the embryo. However, the ease of mechanical transmission to healthy cucurbit seedlings through mechanical transmission using tissue extract prepared from CGMMV-contaminated seeds meant it was likely the main route of virus transmission. From this initial infection focus, the virus could be disseminated to other areas through contacts from contaminated hands, tools, or dirty clothing, especially in the intensive protected cultivation and seed production fields. Because the practice of grafting melon and watermelon plants onto other cucurbit rootstocks (including Cucurbita interspecific hybrid, bottle gourd, or wild watermelon) has become routine, risk of a CGMMV outbreak owing to the use of a contaminated seed lot has also been enhanced. Early studies have reported on a seed-to-seedling transmission rate of CGMMV on watermelon at $2.25 \%$, on melon at $2.83 \%$ (Wu et al. 2011), and on bottle gourd at $2 \%$ (Choi 2001). Although we did not observe seed-to-seedling transmission in a smaller number of experimental seeds of watermelon through seedling grow-out, the elevated $\mathrm{Ct}$ value detected in qRT-PCR may be owing to inactive virus particles carried over in the cotyledon and first true leaf, because no systemic infection of CGMMV developed on these putatively positive plants as the plants were growing older. Moreover, we demonstrated that CGMMV could be transmitted mechanically from a contaminated seed to a healthy seedling, resulting in a new infection from one of three seeds tested, which poses a higher risk to cucurbit growers if using a contaminated seed lot. The high rate of mechanical transmission from contaminated seeds to seedlings could serve as a primary inoculum for CGMMV epidemics in cucurbit crop production. Therefore, there is an urgent need to evaluate the various methods of CGMMV detection to achieve the most effective and reliable seed health assays to prevent the introduction and outbreak of CGMMV during cucurbit production.

Although a number of virus detection methods have been developed for CGMMV (Chen et al. 2008; Kim et al. 2003; Varveri et al. 2002; Zhang et al. 2009), currently there is no standard seed health assay available to achieve sensitive and reliable testing of commercial cucurbit seeds. The recent outbreaks of CGMMV in Canada, the United States, and Australia (Ling et al. 2014; Tesoriero et al. 2015; Tian et al. 2014) have resulted in stricter requirements in seed health testing on imported seeds from various countries. Therefore, we were interested in evaluating various virus detection

Table 1. Enzyme-linked immunosorbent assay evaluation of mechanical transmission of cucumber green mottle mosaic virus from contaminated seeds to healthy melon seedlings

\begin{tabular}{lcccc}
\hline Sample & $\begin{array}{c}\text { Plant } \\
\text { replicate }\end{array}$ & Mean absorbance \pm SD & Result & \% Infection \\
\hline $570-1$ & 1 & $-0.007 \pm 0.008$ & - & $0 \%$ \\
& 2 & $-0.009 \pm 0.002$ & - & \\
$570-2$ & 3 & $-0.031 \pm 0.004$ & - & \\
& 1 & $-0.015 \pm 0.016$ & - & $0 \%$ \\
& 2 & $0.004 \pm 0.018$ & - & \\
$570-3$ & 3 & $0.004 \pm 0.003$ & - & \\
& 1 & $2.352 \pm 0.071$ & + & $33.3 \%$ \\
& 2 & $0.043 \pm 0.012$ & - & \\
\hline
\end{tabular}


methods for their suitability for testing for CGMMV in cucurbit seeds. Through these comparative evaluations, our results demonstrated that the new ELISA kit of CGMMV recently developed by Agdia using a new antibody generated from a purified virus preparation produced the most consistent results in reaching a reliable conclusion. Although other sources of ELISA kits may also be useful, they were not evaluated in this study. The ImmunoStrip is the most convenient method for CGMMV detection in leaf tissue samples, providing a result in 5 to 10 min using crude tissue extract. However, in seed health tests, owing to a general lower virus titer on contaminated seeds than in infected leaf tissue, the positive lines appeared to be much weaker and slower than that of leaf samples (Fig. 3B). Despite this limitation, the ImmunoStrip could be an alternative method to confirm putative samples in borderline readings from an ELISA test. The third test method was RT-LAMP, which produced extremely high sensitivity with less time and no need for an expensive instrument. This new RT-LAMP assay was developed using primers from conserved sequences to all known CGMMV isolates, including both Asian and European genotypes. The previous RT-LAMP (Li et al. 2013) was developed based primarily using conserved sequences for the Asian genotype of CGMMV. This new LAMP assay developed in the present study was specific to CGMMV, with no cross-reaction to two other seed-borne viruses, SqMV and MNSV. In comparison with the previous RT-LAMP, the loop primers were also included in the present study to enhance sensitivity. Taken together, the present RT-LAMP assay is a rapid, reliable, and simple method to achieve high sensitivity for CGMMV detection, which could be further developed for seed health assays, especially on RNA extracts from a large number of seeds. Similar issues occurred in qRT-PCR experiments in the processing of a large quantity of seed tissue for purified total plant RNA that is useful for a seed health assay. Our preliminary test results using crude sample preparations in qRT-PCR were poor; thus, improvements in RNA extraction from seed tissue would be necessary. Through these comparative evaluations, ELISA reagents have achieved the most consistent results, which could be recommended for seed health testing of cucurbit

Table 2. Comparative sensitivity of four virus detection methods used for seed health tests of cucumber green mottle mosaic virus (CGMMV) ${ }^{\mathrm{a}}$

\begin{tabular}{lcccc}
\hline Sample $^{\mathbf{b}}$ & ELISA & ImmunoStrip & qRT-PCR & RT-LAMP \\
\hline $1: 300$ & + & + & $?$ & + \\
$1: 500$ & + & + & $?$ & + \\
$1: 1,000$ & + & + & $?$ & + \\
$1: 2,000$ & + & + & - & + \\
$1: 3,000$ & + & + & - & - \\
$1: 5,000$ & + & + & - & - \\
NTC & - & - & - & - \\
Healthy & - & - & - & - \\
CGMMV control & + & + & + & + \\
\hline
\end{tabular}

${ }^{\text {a }}$ ELISA = enzyme-linked immunosorbent assay; qRT-PCR = real-time quantitative reverse transcription polymerase chain reaction; and RT-LAMP = reverse transcription loop-mediated isothermal amplification. Symbols indicate the presence of CGMMV detected in the seed samples: $+=$ positive result; $-=$ negative result; and $?=$ inconclusive borderline cycle threshold $(\mathrm{Ct})$ reading.

${ }^{\mathrm{b}}$ Spike one CGMMV-infected watermelon seed in number of healthy cantaloupe seeds as indicated. NTC $=$ nontemplate control.
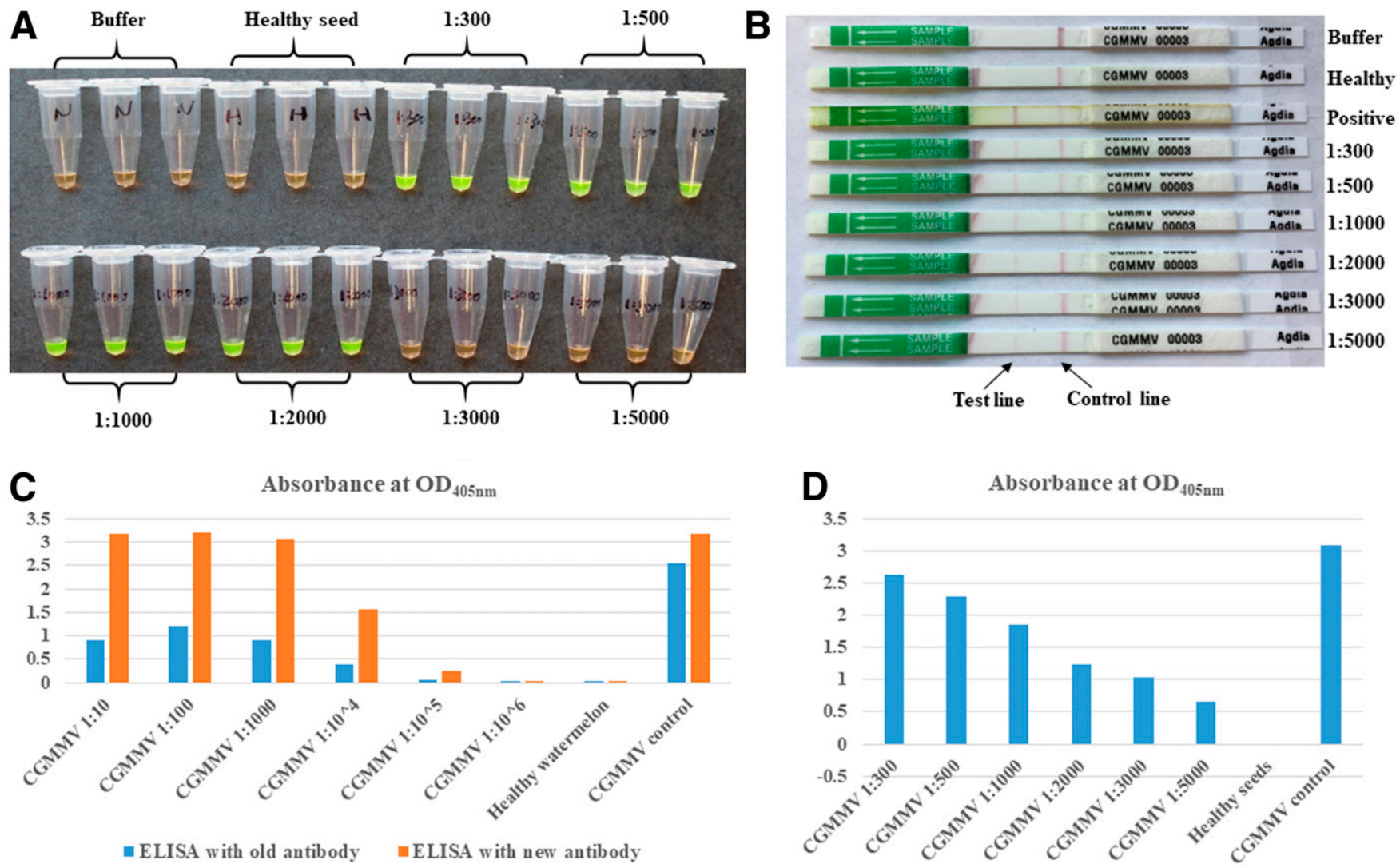

Fig. 3. Comparative evaluation of loop-mediated isothermal amplification (LAMP), ImmunoStrip, and enzyme-linked immunosorbent assay (ELISA) to detect cucumber green mottle mosaic virus (CGMMV) on seed and leaf tissues. A, Seed health test using CGMMV-specific reverse transcription LAMP assay. Three replicates of samples were prepared in a series of dilutions, and the results were visualized through staining with SYBR Green I. Samples in green color were positive, and those with orange color were negative. B, Seed health testing for CGMMV using ImmunoStrip. Seed dilutions were prepared by spiking one CGMMV-infected seed to the designated number of uninfected melon seeds. Positive control is CGMMV-infected watermelon leaf tissue. Healthy control is an uninfected tissue. C, Comparative analysis of an old and a new version of ELISA kits from Agdia for CGMMV detection. Sensitivity of detection was determined using serial 10-fold dilutions of CGMMV-infected watermelon leaf tissue. D, Sensitivity of a seed health assay using a new ELISA kit. ELISA test was conducted using serial 10-fold dilutions of seed extract prepared from samples spiked with a CGMMV-infected seed into designated number of clean melon seeds. 
seeds for CGMMV, because of the sensitivity, stability, and ease of use on a large quantity of seed samples.

In this study, we compared the two commonly used bioassay methods, seedling grow-out and mechanical transmission using seed extract. From our results, we were surprised to find out that seedling grow-out is not a proper means to assess the seed transmission of CGMMV in a contaminated seed sample. However, a bioassay conducted on a sensitive cucurbit plant would offer a more meaningful risk assessment to the virus infectivity on a contaminated seed lot.

In conclusion, CGMMV is a seed-borne and highly contagious virus. Although a new infection might not result from a natural seedling grow-out, mechanical transmission could occur when a CGMMVcontaminated seed extract is inoculated on test healthy cucurbit seedlings. Therefore, a sensitive seed health test is necessary to ensure virus-free seed lots are used for planting. However, to achieve a realistic risk assessment, an effective bioassay is necessary to determine the viability of virus particles detected through a laboratory test. For comparative evaluation of various seed health test methods, serological ELISA and molecular RT-LAMP offered greater sensitivity and reliability. A lateral flow device (ImmunoStrip) may be useful for a quick confirmation, but improvement to RNA extraction on cucurbit seed would be necessary if qRT-PCR is to be useful for a seed health assay.

\section{Acknowledgments}

We thank Andrea Gilliard for her excellent technical assistance. Agdia's generous gifts on their newly developed ELISA and ImmunoStrip kits against CGMMV are greatly appreciated.

\section{Literature Cited}

Ainsworth, G. C. 1935. Mosaic diseases of the cucumber. Ann. Appl. Biol. 22: $55-67$

Ali, A., Natsuaki, T., and Okuda, S. 2004. Identification and molecular characterization of viruses infecting cucurbits in Pakistan. J. Phytopathol. 152:677-682.

Antignus, Y., Pearlsman, M., Benyoseph, R., and Cohen, S. 1990. Occurrence of a variant of cucumber green mottle mosaic virus in Israel. Phytoparasitica 18: $50-56$.

Australian Government Department of Agriculture and Water Resources. 2017. Final pest risk analysis for cucumber green mottle mosaic virus (CGMMV), Department of Agriculture and Water Resources, Canberra. http://www. agriculture.gov.au/SiteCollectionDocuments/biosecurity/risk-analysis/plantreviews/final-pest-risk-analysis-cgmmv.pdf. Accessed October 12, 2018.

Borodynsko-Filas, N., Minicka, J., and Hasiow-Jaroszewska, B. 2017. The occurrence of cucumber green mottle mosaic virus infecting greenhouse cucumber in Poland. Plant Dis. 101:1336.

Budzanivska, I., Rudneva, T., Shevchenko, T., Boubriak, I., and Polischuk, V. 2007. Investigation of Ukrainian isolates of cucumber green mottle mosaic virus. Arch. Phytopathol. Plant Prot. 40:376-380.

CABI. 2015. Cucumber green mottle mosaic virus (white break mosaic). Crop Protection Compendium Datasheet 16951. https://www.cabi.org/cpc/ datasheet/16951. CABI, Wallingford, U.K.

CABI/EPPO. 2015. Cucumber green mottle mosaic virus. In: Distribution Maps of Plant Diseases, Map 1174. https://www.cabi.org/dmpd. CABI, Wallingford, U.K.

Chen, H., Zhao, W., Gu, Q., Chen, Q., Lin, S., and Zhu, S. 2008. Real time TaqMan RT-PCR assay for the detection of cucumber green mottle mosaic virus. J. Virol. Methods 149:326-329.

Chen, H. Y., Zhao, W. J., Cheng, Y., Li, M. F., and Zhu, Y. F. 2006. Molecular identification of the virus causing watermelon mosaic disease in middle of Liaoning. Acta Phytopathol. Sin. 36:198-200.

Choi, G. S. 2001. Occurrence of two tobamovirus diseases in cucurbits and control measures in Korea. Plant Pathol. J. 17:243-248.

Dombrovsky, A., Tran-Nguyen, L. T. T., and Jones, R. A. C. 2017. Cucumber green mottle mosaic virus: Rapidly increasing global distribution, etiology, epidemiology, and management. Annu. Rev. Phytopathol. 55:231-256.

Kim, S. M., Nm, S. H., Lee, J. M., Yim, K. O., and Kim, K. H. 2003. Destruction of cucumber green mottle mosaic virus by heat treatment and rapid detection of virus inactivation by RT-PCR. Mol. Cells 16:338-342.

Le, D. T., Netsu, O., Tamake, U. I., Shimizu, T., Choi, I. R., Omura, T., and Sasaya, T. 2010. Molecular detection of nine rice viruses by a reversetranscription loop-mediated isothermal amplification assay. J. Virol. Methods 170:90-93.
Li, J. Y., Wei, Q. W., Liu, Y., Tan, X. Q., Zhang, W. N., and Wu, J. Y. 2013. Onestep reverse transcription loop-mediated isothermal amplification for the rapid detection of cucumber green mottle mosaic virus. J. Virol. Methods 193: 583-588.

Li, R., Fei, Z., and Ling, K. S. 2014. Molecular and biological properties of tomato necrotic stunt virus and development of a sensitive real-time RT-PCR assay. Arch. Virol. 159:353-358.

Li, R., and Ling, K. S. 2014. Development of reverse transcription loop-mediated isothermal amplification assay for rapid detection of an emerging potyvirus: Tomato necrotic stunt virus. J. Virol. Methods 200:35-40.

Ling, K. S., Li, R., and Zhang, W. 2014. First report of cucumber green mottle mosaic virus infecting greenhouse cucumber in Canada. Plant Dis. 98:701.

Liu, H. W., Luo, L. X., Li, J. Q., Liu, P. F., Chen, X. Y., and Hao, J. J. 2014. Pollen and seed transmission of cucumber green mottle mosaic virus in cucumber. Plant Pathol. 63:72-77.

Liu, L., Peng, B., Zhang, Z., Wu, Y., Miras, M., Aranda, M. A., and Gu, Q. 2017 Exploring different mutations at as single amino acid position of cucumber green mottle mosaic virus replicase to attain stable symptom attenuation. Phytopathology 107:1080-1086.

Liu, Y., Wang, Y., Wang, X., and Zhou, G. 2009. Molecular characterization and distribution of cucumber green mottle mosaic virus in China. J. Phytopathol. 157:393-399.

Liu, Y., Wang, Z., Qian, Y., Mu, J., Shen, L., Wang, F., and Yang, J. 2010. Rapid detection of tobacco mosaic virus using the reverse transcription loop-mediated isothermal amplification method. Arch. Virol. 155:1681-1685.

Mandal, S., Mandal, B., Mohd, Q., Haq, R., and Varma, A. 2008. Properties, diagnosis and management of cucumber green mottle mosaic virus. Plant Viruses 2:25-34.

Massumi, M., Asghar, S., Akbar, H. P., and Mehdi, S. 2007. Occurrence distribution and relative incidence of seven viruses infecting greenhousegrown cucurbits in Iran. Plant Dis. 91:159-163.

Nematollahi, S., Haghtaghi, E., Koolivand, D. L., and Hajizadeh, M. 2014 Molecular detection of cucumber green mottle mosaic virus variants from cucurbits fields in Iran. Arch. Phytopathol. Plant Prot. 47:1303-1310.

Norwegian Scientific Committee for Food Safety. 2008. Pest Risk Assessment of the Cucumber Green Mottle Mosaic Virus in Norway. VKM Report 2008:07. https://vkm.no/download/18.d44969415d027c43cf1598e/1500387338796/ c4303083c8.pdf.

Notomi, T., Okayama, H., Masubuchi, H., Yonekawa, T., Watanabe, K., Amino, N., and Hase, T. 2000. Loop-mediated isothermal amplification of DNA Nucleic Acids Res. 28:e63.

Reingold, V., Lachman, O., Blaosov, E., and Dombrovsky, A. 2015. Seed disinfection treatments do not sufficiently eliminate the infectivity of cucumber green mottle mosaic virus (CGMMV) on cucurbit seeds. Plant Pathol. 64:245-255.

Reingold, V., Lachman, O., Koren, A., and Dombrovsky, A. 2013. First report of cucumber green mottle mosaic virus (CGMMV) symptoms in watermelon used for the discrimination of non-marketable fruits in Israeli commercial fields. Plant Pathol. 28:11.

Shim, C. K., Han, K. S., Lee, J. H., Bae, D. W., Kim, D. K., and Kim, H. K. 2005. Isolation and characterization of watermelon isolate of cucumber green mottle mosaic virus (CGMMV-HY1) from watermelon plants with severe mottle mosaic symptoms. J. Plant Pathol. 21:167-171.

Slavokhotova, A. A., Istomina, E. A., Andreeva, E. N., Korostyleva, T. V., Pukhalskij, V. A., Shijan, A. N., and Odintsova, T. I. 2016. An attenuated strain of cucumber green mottle mosaic virus as a biological control agent against pathogenic viral strains. Am. J. Plant Sci. 7:724-732.

Tesoriero, L. A., Chambers, G., Srivastava, M., Smith, S., Conde, B., and TranNguyen, L. T. T. 2015. First report of cucumber green mottle mosaic virus in Australia. Australas. Plant Dis. Notes 11:1-3.

Tian, T., Posis, K., Maroon-Lango, C. J., Mavrodieva, V., Haymes, S., Pitman, T. L., and Falk, B. W. 2014. First report of cucumber green mottle mosaic virus on melon in the United States. Plant Dis. 98:1163.

Varveri, C., Vassilakos, N., and Bem, F. 2002. Characterization and detection of cucumber green mottle mosaic virus in Greece. Phytoparasitica 30:493-501.

Wu, H. J., Qin, B. X., Chen, H. Y., Peng, B., Cai, J. H., and Gu, Q. S. 2011. The rate of seed contamination and transmission of cucumber green mottle mosaic virus in watermelon and melon. Sci. Agric. Sin. 44:527-532.

Yoon, J. Y., Choi, G. S., Choi, S. K., Hong, J. S., Choi, J. K., Kim, W., Lee, G. P., and Ryu, K. H. 2008. Molecular and biological diversities of cucumber green mottle mosaic virus from cucurbitaceous crops in Korea. Phytopathology 156:408-412

Zhang, Y. J., Li, G. F., and Li, M. F. 2009. Occurrence of cucumber green mottle mosaic virus on cucurbitaceous plants in China. Plant Dis. 93:200.

Zhou, T., Du, L., Fan, Y., and Zhou, Y. 2012. Reverse transcription loop-mediated isothermal amplification of RNA for sensitive and rapid detection of Southern rice black-streaked dwarf virus. J. Virol. Methods 180:91-95. 